www.jmscr.igmpublication.org

Impact Factor 5.84

Index Copernicus Value: 71.58

ISSN (e)-2347-176x ISSN (p) 2455-0450

crossref DOI: https://dx.doi.org/10.18535/jmscr/v5i11.184

Journal Of Medical Science And Clinical Research

An Official Publication of IGM Publication

\title{
Knowledge and Practices of Mothers of under Five Children on Prevention of Selected Water Borne Diseases At Israelpet, Guntur (Dt.), A.P.
}

\author{
Authors \\ N. Srilaxmi ${ }^{1}$, R. Priscilla Inbarathi ${ }^{2}$, S. Gomathi ${ }^{3}$ \\ ${ }^{1}$ MSc Nursing Student, ${ }^{2}$ Professor, ${ }^{3}$ Associate Professor, \\ NRI College of Nursing, Chinakakani, Guntur (Andhra Pradesh) \\ Email: gmpsai12@gmail.com
}

\begin{abstract}
Background: Water borne diseases are the most emerging and re-emerging infectious diseases causing morbidity and mortality among under five age group children throughout the world. Mothers knowledge about water borne diseases and it's prevention depends upon various factors such as age of the mother, religion, educational background, occupation, number of children, family income per month, type of family, source of drinking water, type of excreta disposal, type of drainage system, source of information. The present study was undertaken to assess the knowledge and practices of mothers of under five children on prevention of selected water borne diseases.

Methodology: A descriptive study was conducted in a urban area of Israelpet, Guntur district among mothers of under five children in December 2016. A structured questionnaire \& checklist was used for data collection among 150 mothers. Data was entered into MS excel sheet and analyzed by using descriptive and inferential statistics.

Results: Among the mothers of under five children 72 (48\%) had inadequate knowledge on water borne diseases and its prevention, followed by 56 (37.3\%) had moderately adequate knowledge and only few 22 (14.7\%) mothers of under five children had adequate knowledge and most of the mothers of under five children had 100 (66.7\%) moderately adequate practices, followed by 30 (20\%) had inadequate practices and only 20 (13.3\%) mothers of under five children had adequate practices on prevention of selected water borne diseases. Both knowledge and practices of mothers had significant association with the age and educational background at $p<0.05$ levels.

Conclusion: The present study shows that most of the mothers were not having adequate knowledge on prevention of selected water borne diseases. The knowledge and practices scores were strong positively correlated. There is a need to educate the mothers about water borne diseases and its prevention.

Keywords: Assess, knowledge, practices, prevention water borne diseases i.e., Cholera, Typhoid and Acute gastroenteritis mothers of under five children.
\end{abstract}

\section{Introduction}

Water borne diseases are any diseases which spread through drinking contaminated water. Water borne diseases include diseases such as cholera, typhoid, shigella, polio, meningitis, hepatitis $\mathrm{A}$ and $\mathrm{E}^{[1]}$. Globally, water borne diseases are the second leading cause of death in children below the age of five years, whereas childhood mortality rates from acute respiratory infections ranks first ${ }^{[2]}$. Typhoid fever also known 
as typhoid is a symptomatic bacterial infection due to salmonella typhi. It is largely a disease of developing nations due to poor sanitation and poor hygiene. It is spread by eating food and water contaminated by faeces of an infected person. Globally, typhoid fever is an important cause of morbidity and mortality in many regions of the world with an estimated 12-33 million cases leading to $2,16,000-6,00,000$ deaths annually ${ }^{[3]}$. Cholera is an infectious disease that causes severe watery diarrhea, which can lead to dehydration and even death if untreated. It is caused by eating food or drinking water contaminated with a bacterium called Vibrio cholera. The outbreak of cholera occurs seasonally and is associated with poor nutrition and poverty that is why it is a disease that occurs mostly in developing countries. Due to cholera so many people died which is estimated as $18,30,40,000$ in a year ${ }^{[1,4]}$. In underdeveloped and developed countries, acute gastroenteritis involving diarrhoea is the leading cause of mortality in infants and children younger than 5 years of age. Rotavirus is a leading cause of severe acute gastroenteritis requiring hospitalizetion among infants and young children worldwide. Previous studies in the Indian Rotavirus Strain Surveillance Network have confirmed that rotavirus accounts for $39 \%$ of acute diarrhoeal hospitalizations $^{[5]}$.

In India, over one lakh people die due to waterborne diseases annually and India's water quality is poor - It ranks 120th among the 122 nations in terms of quality of water available to its citizens ${ }^{[6]}$. Researchers have estimated that there are 1.4 to 4.3 million cases and 28,000 to $1,42,000$ deaths worldwide due to cholera, whereas typhoid fever accounts for about 6,00,000 deaths among under five children and acute gastroenteritis 2,00,000 deaths ${ }^{[7]}$. According to 'National Health Profile' published by Central Bureau of Health Investigation, Directorate General of Health Sciences, Ministry of Health and Family Welfare, Government of India (2013) reported that from [2011-2013] in Andhra Pradesh there are $17,21,050$ cases and 100 deaths due to acute diarrhoeal diseases, 2,33,212 cases and 5 deaths due to typhoid and 31 cases due to cholera ${ }^{[8]}$.

Studies conducted in India indicate that water borne diseases are one of the leading killers of children worldwide. As per the study conducted by Priti Choudhary (2014) showed that $96 \%$ of the mothers defined diarrhoea appropriately. Though 83\% mothers believed that cleaning drinking water prevents diarrhoea, yet water treatment was practiced by only $36 \%{ }^{[9]}$."Health for all by 2025 AD" will remain a dream unless the mothers of under five children gain enough information regarding water borne diseases. If no action is taken to address unmet basic human needs for water, as many as 135 million people will die from these diseases by 2020 . Water borne diseases are simple to explain but very complex to understand $^{[10]}$. Swachh Bharat Abhiyan is a Swachh Bharat mission led by the government of India to "make India a clean India", covering 4, 041 cities and towns, to clean the streets, roads and infrastructure of the country. It has been implemented in urban areas with focus on construction of individual household, community and public toilets to eradicate open defecation and disposal of solid waste in urban areas. But still many of the communities were not following it which is one of the aspects to prevent diseases related to water contamination and poor sanitation [11]. Mothers are the key caregivers for children under five year old. They are the one who can decide about the prevention of water borne diseases in children therefore their knowledge about this common disorder is critically important. Hence there is a need to undertake a study to assess the knowledge and practices of mothers of under five children on prevention of selected water borne diseases.

Conceptual framework used for the study was Rosenstock's and Becker's Modified Health Belief Model (1974) which includes three basic components individual perceptions, modifying factors \& Likelihood of action. 


\section{Methodology}

A descriptive correlation design was chosen for the study. The study was conducted on community based during the period of $15^{\text {th }}$ December 2016 to $1^{\text {st }}$ January 2017. As per 2016 census, the total population of Israelpet area, Guntur district consists of 16,564 among this about 1,816 people were the mothers of children of under five. All the mothers with at least one under five child and who were willing to participate were included in the study. Mothers with no under five child and who were not willing to participate were excluded from the study. Samples of 150 mothers were drawn to include in the study by using Simple random sampling technique. Institutional ethical committee and prior permission from Medical Officer was taken before starting the data collection.

The interviewees were informed about the purpose and nature in their local language. A structured questionnaire was used for data collection. The structured questionnaire consists of three sections covering the socio-demographic variables, structured questionnaire on knowledge and checklist on prevention of selected waterborne diseases. The questions were framed into thirty multiple choice questions giving more than one option for all the questions and a checklist of twenty five items, with two options. Content validity of the tool was done by experts and the reliability of the tool was done by splithalf method which was reliable. Pilot study was conducted at Sangadigunta Urban population, Guntur district which showed whole questionnaire were found to be feasible and easily understandable by the subjects. The structured questionnaire was given to the mothers who were present at the time of data collection by using personal interview method in Telugu.

\section{Statistical Analysis}

Data were entered into MS excel sheet and analysis was done by using descriptive and inferential statistics. Frequency and percentage were used to summarize the sample characteristics and for item wise analysis. Mean and Standard deviation were used to assess the knowledge and practices of mothers of under five children on prevention of selected waterborne diseases. Chisquare values computed to find out the association between the knowledge and practices with selected variables Karl Pearson's correlation coefficient computed to correlate knowledge and practices of mothers of under five children on prevention of selected water borne diseases.

\section{Results}

In the study the Socio-demographic details (Table 1) suggest that majority of the respondents $(50.7 \%)$ were in the age group of less than 20 years. Among all mothers majority of them (43.3\%) had two children, $42.7 \%$ were having one child and $14 \%$ were having three or more children during the study period. Majority of the respondents $(42.7 \%)$ belonged to Muslim religion. Most of the respondents (32\%) were educated only from $1^{\text {st }}$ to $10^{\text {th }}$ class and $43.3 \%$ were Unemployed. Majority (43.3\%) of the children belonged to nuclear family.

Table 1: Socio-demographic variables of the respondents

\begin{tabular}{|l|c|c|}
\hline Socio-demographic variables & Frequency(f) & Percentage(\%) \\
\hline Number of children & & \\
One child & 64 & 42.7 \\
Two child & 65 & 43.3 \\
Three or more & 21 & 14 \\
\hline Religion & 55 & \\
Hindu & 64 & 36.7 \\
Muslim & 31 & 42.7 \\
Christian & & 20.6 \\
\hline Education of mother & 26 & 17.3 \\
Knows to read and write & 48 & 32 \\
$1^{\text {st }}$-10 class & 41 & 27.3 \\
Intermediate & 35 & 23.3 \\
Graduation and above & & \\
\hline Occupation of mother & 65 & 43.3 \\
House wife & 85 & 56.7 \\
Working woman & 106 & \\
\hline Source of drinking water & 0 & 0.7 \\
Municipal water & 44 & 29.3 \\
Well water & 150 & 100 \\
Bore water & 0 & 0 \\
\hline Type of drainage system & & \\
Open drainage & & \\
Closed drainage & & \\
\hline
\end{tabular}


In the present study majority of the respondents (70.7\%) were using municipal water and $29.3 \%$ were drinking bore well water. Almost all the respondents $(100 \%)$ were using sanitary latrines for excreta disposal and were using open type of drainage system. The respondents got information on prevention of selected water borne diseases from various sources like $42.6 \%$ from health personnel's, $28.7 \%$ through media, $14.6 \%$ through newspaper and $14 \%$ through friends and relatives.

\section{Knowledge about selected water borne diseases}

Among 150 mothers 85 (56.7\%) knew that under 5 years children were commonly affected due to water borne diseases, $62(41.3 \%)$ thought that untreated water is the main cause of water borne diseases. 63(42\%) respondents were aware about the common route for gastroenteritis is faecal-oral route. Seventy nine (52.7\%) respondents had correctly answered that consuming food and water contaminated with faecal matter is the cause for typhoid fever. Sixty one (40.7\%) respondents knew that the early symptoms of typhoid fever are fever, headache and abdominal pain. Eighty eight (58.7\%) respondents know that chlorine is the disinfectant commonly used for water treatment. Fifty eight $(38.7 \%)$ respondents answered that the recurrence of typhoid can be prevented by the use of full course of prescribed antibiotics. Twenty six $(17.3 \%)$ respondents were aware that watery stool is the characteristic feature of stool in cholera. Eighty seven (58\%) respondents gave correct response as to preparation of ORS that is one ORS sachet in one litre of boiled cooled water, $83(55.3 \%)$ knew that prepared ORS should be used within 24 hours and 80(53.3\%) respondents knew about the home made preparation of ORS. Only 72 out of $150(48 \%)$ were aware the rotavirus vaccine is available to reduce the risk for gastroenteritis.
Fig 1: Mean and Standard Deviation for knowledge on prevention of selected water borne diseases

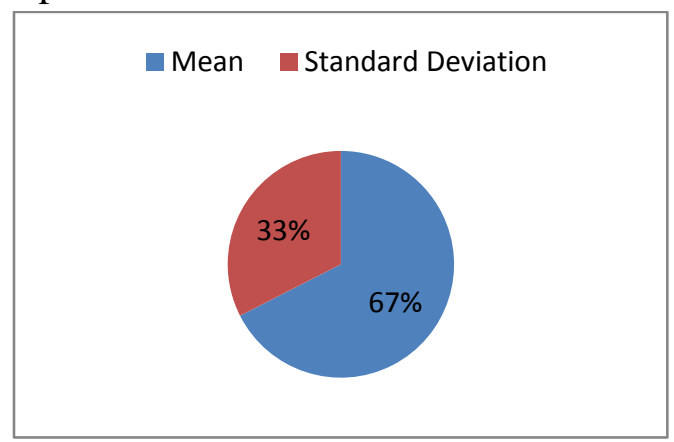

The mean score of knowledge level was 14.70 with the standard deviation 7.08.

Table 2: Knowledge scores on prevention of selected water borne diseases

\begin{tabular}{|l|c|c|}
\hline Level Of Knowledge & $\mathrm{F}$ & $\%$ \\
\hline Adequate knowledge $(>76 \%)$ & 22 & 14.7 \\
Moderately adequate knowledge $(51-75 \%)$ & 56 & 37.3 \\
Inadequate knowledge $(\leq 50 \%)$ & 72 & 48 \\
\hline
\end{tabular}

Overall most of the mothers of under five children had 72 (48\%) inadequate knowledge, 56 (37.3\%) moderately adequate knowledge and only 22 $(14.7 \%)$ had adequate knowledge.

\section{Practices about water borne diseases}

Among 150, only 18 (12\%) practice boiling water before drinking, 44 (29.3\%) were using bore water for drinking, $121(80.6 \%)$ keep their toilets clean, $138(92 \%)$ use soap for hand washing, 58(38.6\%) of their children have the habit of defecating in an open field, 144(96\%) of their children were immunized according to the age and none of the respondent had vaccinated their child with rotavirus vaccine.

Fig 2: Mean and Standard Deviation for practices on prevention of selected water borne diseases

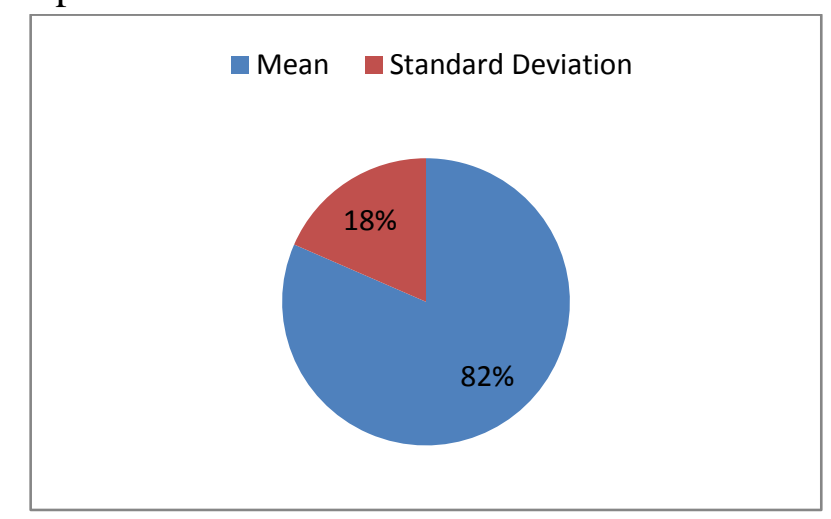

The mean score of practices was 16.02 with the standard deviation 3.63. 
Table 3: Practice scores on prevention of selected water borne diseases

\begin{tabular}{|l|c|c|}
\hline Practices & $\mathrm{F}$ & $\%$ \\
\hline Adequate practices (>76\%) & 20 & 13.3 \\
Moderately adequate practices $(51-75 \%)$ & 100 & 66.7 \\
Inadequate practices ( $\leq 50 \%)$ & 30 & 20 \\
\hline
\end{tabular}

Overall most of the mothers of under five children had $100(66.7 \%)$ moderately adequate practices, $30(20 \%)$ inadequate practices and only 20 (13.3\%) mothers had adequate practices on prevention of selected water borne diseases.

Association of knowledge and practices with their selected variables:

By Chi-square computation both Knowledge and Practices on prevention of water borne diseases, showed significant association with age (knowledge- $\left.\chi^{2}=28.54\right) \quad\left(\right.$ practices $\left.-\chi^{2}=18.54\right)$ and educational background (knowledge- $\chi^{2}=43.78$ ) (practices- $\chi^{2}=17.02$ ).

Table 4: Relationship between the knowledge and practices

\begin{tabular}{|c|c|}
\hline Item & $\begin{array}{c}\text { Pearson's coefficient } \\
\text { correlation }\end{array}$ \\
\hline Knowledge and Practice & 0.595 \\
\hline
\end{tabular}

The table 4 shows that knowledge and practices were strong positively correlated.

\section{Discussion}

In the study it was found that majority of the respondents $(50.7 \%)$ were in the age group of less than 20 years and $(42.7 \%)$ have one child. Majority of them (42.7\%) belonged to Muslim religion. Majority of them have primary education $(32 \%)$ that is from $1^{\text {st }}$ to $10^{\text {th }}$ class. Majority (43.3\%) of the children belonged to nuclear family. In context with safe drinking water supply, majority of the respondents $(70.7 \%)$ were using municipal water. Almost all the respondents $(100 \%)$ were using sanitary latrines for excreta disposal and were using open type of drainage system. Majority of them (42.6\%) got information from health personnel's during health visits.

In the study it was found that $26(17.3 \%)$ respondents were aware that watery stool is the characteristic feature of stool in cholera which was similar with a study conducted at Dhaka $23 \%{ }^{[12]}$.Knowledge related to ORS, in the study it was found that $87(58 \%)$ knew about the correct preparation of ORS where a similar response was seen in the study conducted at Nigeria $(60.3 \%)^{[13]}$. The knowledge about homemade preparation of ORS in the study shows 80(53.3\%). Similar observation was made by the another study conducted in Nigeria $(40 \%)^{[13]}$. In the study $29.3 \%$ were using bore water as a source of drinking water which is similarly seen in the study conducted at Nigeria $(26 \%)^{[13]}$.Only few practice boiling water before drinking which was similar to the studies conducted at Nammakal district 93\% were not using any method of purification.

Mother's knowledge is important on prevention of selected water borne diseases. In the study majority of the respondents $72(48 \%)$ had inadequate knowledge, 56 (37.3\%) had moderately adequate knowledge and only $22(14.7 \%)$ had adequate knowledge on prevention of selected water borne diseases. The study shows poor knowledge on prevention of selected water borne diseases (14.7 \pm 7.08) which was supported by the study in Limpopo, South Africa showed that majority of the respondents had no knowledge on water based diseases and its prevention $(78 \pm 1.71)^{[14]}$.

Based on the practices, majority of the respondents $100(66.7 \%)$ had moderately adequate practices, $30(20 \%)$ had inadequate practices and only $20(13.3 \%)$ had adequate practices on prevention of selected water borne diseases. The practice level on prevention of selected water borne diseases was moderately adequate (16.02 \pm 3.63). Both Knowledge and Practices showed significant association with age (knowledge$\left.\chi^{2}=28.54\right) \quad\left(\right.$ practices $\left.-\chi^{2}=18.54\right)$ and educational background (knowledge- $\left.\chi^{2}=43.78\right) \quad$ (practices$\chi^{2}=17.02$ ). Similarly it is seen in the studies conducted at Rupena ${ }^{[9]}$ which showed a significant relationship between education with the knowledge of mothers regarding waterborne diseases and its prevention and in Dhaka ${ }^{[15]}$ and in Karnataka at $(\mathrm{P}<0.001){ }^{[16]}$. A strong positive relationship was found between the knowledge and practices $(r=0.595)$ of mothers of under five 
children on prevention of selected water borne diseases.

\section{Conclusion}

From this study it was concluded that majority of the respondents were having inadequate knowledge on prevention of selected water borne diseases. Many of them were not aware about the causes of water borne diseases, its transmission routes and the early symptoms. Many were not aware about the preventive measures such as with regard to additional vaccines which were available to reduce the risk of water borne diseases such as Rotavirus vaccine for diarrhoea. Practice levels were also found poor with regard to proper hand washing techniques and many of their children were defecating in open field. Current information is essential to understand the challenges of protecting water quality and to address the health effects of water contamination through public and private partnership by conducting various health education campaigns.

\section{Acknowledgement}

We acknowledge mothers for their cooperation and participation in sharing their information on prevention of water borne diseases.

\section{References}

1. K Park.Textbook of preventive and social medicine. $24^{\text {th }}$ ed.Jabalpur:Banarsidas Bhanot Publishers 2017;p.747.

2. Sneha Rajan.ForbesIndia Magazine.Unitus seed fund.2015 JU1 21.

3. Okore Oghale O'woma, Ubiaru Prince Chigozirim, Nwaogwugwu Uzoamaka Gloria. American Journal of Public Health Research. Prevalence of Malaria and Typhoid fever co-infection: Knowledge, Attitude and Management practices among residents of Obuda-aba, Abia state, Nigeria. Vol. 3, No 4, 2015.p.162-166.

4. Rao KS.An introduction to community nursing. $3^{\text {rd }}$ ed.New Delhi:B.J. Publishers; 2000 .
5. Jamiu. M. Olakunle, Odili Valentine V, Abu-saeed Kamaldeen, Abu-saeed Muhammad Buhari. Assessment of mother's knowledge of home management of childhood diarrhoea in Nigerian setting. International Journal of Pharmaceutical research and Bio-science. IJPRBS, 2012; Vol.1 (4): 168-184.

6. Ajay Pal Singh Chabba.Water borne diseases in India. Varanasi.31-05-2013.

7. Ali M, Lopez AL, You YA, et al. The global burden of cholera. Buletin World Health Organization; 2012: 90: 209-18A.

8. Press Information Bureau. Government of India. Ministry of health and family welfare-15-July-2014. 13:42 IST WaterBorne diseases.

9. Priti Chaudhary,saurav basu,Anthony Kevisetuo Dzeye,Sumit Gulla ,Sujata khade,Adarsh Patel,Debasish Phukan,Tanzin Dikid,Anil kumar ,Aakash Shrivastava.Knowledge, Attitudes and Practice of mothers regarding Diarrhoeal Illness in children under five years of age :A cross Sectional study in an Urban slum of Delhi ,India. Vol 46, No 3 (2014).

10. World Health Organization. A report on water borne diseases; 2014.

11. Peter H. Gleik. Dirty water. Estimated death rates from water borne diseases.2000-2020. Pacific institute research report. 2002; Aug.15.

12. Tasnuva Wahed, Shiekh Shah Tanvir Kaukab, Nirod Chandra Saha, Iqbal Ansary khan. A cross-sectional study on knowledge, attitudes and preventive practices related to cholera and oral cholera vaccine among urban high risk groups in Dhaka, Bangladesh. BMC public health 2013, 3: 242.

13. Jamui M.Olakunle, Odili valentine U,Abusaeed ,kamaldeen ,abu-saeed Muhammad buhari.Assessment of mothers knowledge of home management of childhood 
diarrhoea in a Nigerian setting, IJPRBS,2012; Vol. 1(4):168-84.

14. Jerry E. Sibiya and Jabulani Ray Gumbo. Knowledge, Attitude and Practices (KAP) survey on water, sanitation and hygiene in selected schools in Vhembe District, Limpopo, South Africa. IJER. 2013. JUN; 10(6):p.2282-2295.

15. Md. Rafiqul Islam et al. An evidence of soio-economic effects on child's diarrhea in Banagalore. JHS.2015; 5(1):p.1-5.

16. Kiran Kumar Rokkappanavar. A study on knowledge and practices of mothers of under five children on management of diarrhoea in urban field practice area of MRMC, India. International journal of community public health.2016;3(3):705. 